\title{
XLVI. The molecular constitution of water
}

\section{William Sutherland}

To cite this article: William Sutherland (1900) XLVI. The molecular constitution of water , Philosophical Magazine Series 5, 50:306, 460-489, DOI: 10.1080/14786440009463937

To link to this article: http://dx.doi.org/10.1080/14786440009463937

$$
\text { 册 Published online: } 21 \text { Apr } 2009 .
$$

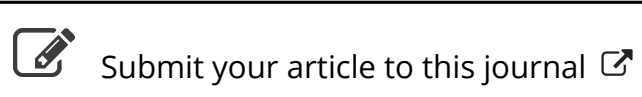

\footnotetext{
Џ Article views: 12
}

Q View related articles $₫$

4 Citing articles: 11 View citing articles 진 


\section{[ 460$]$ \\ XLV1. The Molecular Constitution of Water. By Wicliam Sutherland *}

THE two chief irregularities in the physics of water, namely, its temperature of maximum density near the solidifying point, and its great expansion on solidification, seem to have long ago suggested the idea that water is a mixture of two substances, whose proportions vary with the temperature. In 1892 Röntgen (Wied. Ann. xlv.) in an elegant but brief paper, showed that qualitatively all the prominent exceptional properties of water could be accounted for by considering water at different pressures and temperatures to be a saturated solution of ice in some other form of $\mathrm{H}_{2} \mathrm{O}$. It seemed to me that sufficient data were in existence to enable one to work out quantitatively the actual constitution of water; and $\mathrm{I}$ propose to show that steam being $\mathrm{H}_{2} \mathrm{O}$, ice is pure $\left(\mathrm{H}_{2} \mathrm{O}\right)_{3}$ and water a mixture of $\left(\mathrm{H}_{2} \mathrm{O}\right)_{3}$ and $\left(\mathrm{H}_{2} \mathrm{O}\right)_{2}$ in proportions whose dependence on temperature can be expressed by a simple formula. $\mathrm{As}_{2} \mathrm{O}$ is very generally used as a symbol for water, and as hydrogen oxide is a long name for so important a chemical species as $\mathrm{H}_{2} \mathrm{O}$, I propose for international convenience to call $\mathrm{H}_{2} \mathrm{O}$ hydrol, $\left(\mathrm{H}_{2} \mathrm{O}\right)_{2}$ dihydrol, and $\left(\mathrm{H}_{2} \mathrm{O}\right)_{3}$ trihydrol. Steam is hydrol, ice is trihydrol, and water a mixture of dihydrol and trihydrol. The investigation will be taken in the following order:-

1. Constitution of water from its thermal expansion.

2. Confirmation from optical refraction.

8. Compressibility of water and dissociation of trihydrol into dihydrol by pressure. film.

4. Surface-tension and constitution of water in surface-

5. Latent heat of fusion, specific heat, and latent heat of evaporation.

6. The viscosity of water.

7. Dielectric capacity.

8. The melting of ice as a phenomenon of dissociation, and the higher valency of oxygen.

9. Summary of results.

\section{Constitution of Water from its Thermal Expansion.}

The starting point in this section is Mendeléeff's empirical approximate formula for the thermal expansion of liquids between $0^{\circ} \mathrm{C}$. and their boiling-points, namely, $\rho=\rho_{0}(1-k t)$, which, expressed graphically, as in the figure, with $t$ for

* Communicated by the Author. 
abscissa and $\rho$ for ordinate, gives a straight line such as $X Y$ for an ordinary liquid. But the corresponding graph for water is like the curve CDE in which the ordinate DN represents the maximum density at about $4^{\circ} \mathrm{C}$. If the actual data are plotted on a large scale, the branch $\mathrm{DE}$ looks as if it

Fig. 1.

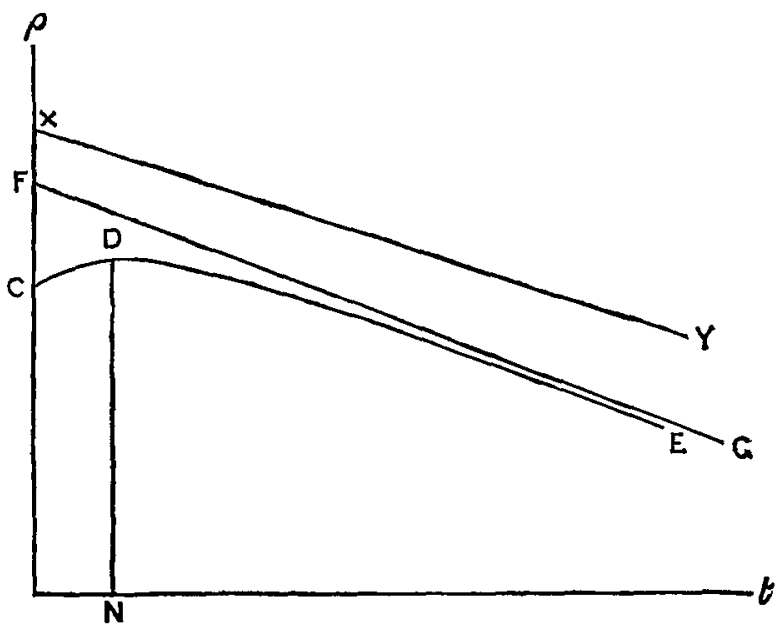

approached asymptotically the straight line FG. The reasonable course is then to assume that this asymptote represents the behaviour of one of the pure ingredients of water. The slope of this asymptote gives for $k$ the value $\cdot 001$, which is of the same order as $k$ for ordinary liquids, and the asymptote cuts the axis of $\rho$ in a point which gives for $\rho_{0}$ for the pure ingredient a value about 1.083 .

Guided by these facts and by theoretical considerations, I sought to obtain an equation for CDE which would give the value of $\rho$ for the other ingredient, and also a law of the dissociation of one ingredient into the other at different temperatures. A preliminary attempt gave a formula which expressed the variation of $\rho$ with $t$ to within 1 part in 10,000 ; but as Mendeléeff (Phil. Mag. [5] xxxiii.) had already furnished an empirical formula for the expansion of water correct to 4 parts in 100,000 , it seemed best to examine his formula in the light of the foregoing considerations. It is

$$
\rho=1-\frac{(t-4)^{2}}{1 \cdot \overline{9}(94 \cdot 1+t)(703 \cdot 51-t)}, \cdots .
$$

Phil. Mag. S. 5. Vol. 50. No. 306. Nov. 1900. 2 K 
which, with the fact that $1_{\prime}^{\prime} 1 \cdot 9=1 / 2+02632$, may be written

$$
\rho=1+\frac{1}{2}-\frac{\cdot 45896}{1-t / 703 \cdot 51}+\cdot 02632-\frac{\cdot 067485}{1+t / 94 \cdot 1} .
$$

To interpret this we must suppose water at $4^{\circ} \mathrm{C}$. to be for the present a standard mixture of the two ingredients in water, and that water at any other temperature is formed by adding a certain proportion of one of the pure ingredients to this standard mixture. Let us denote this standard mixture by $\mathrm{S}$, its density at any temperature by $\rho_{s}$, and at $0^{\circ}$ by $\rho_{0} \rho_{s}$, while $\rho_{1}$ and $\rho_{1}$ relate to the pure ingredient which we shall call 1 . Then for a mixture of $1 / 2+g$ parts by weight of $S$ with $i / 2-q$ parts of 1 formed without shrinking, we should have a density $\rho$ given by

$$
\begin{aligned}
\frac{1}{\rho} & =\frac{1 / 2-q}{\rho_{1}}+\frac{1 / 2+q}{\rho_{s}}=\frac{1}{\rho_{s}}+\left(\frac{1}{2}-q\right)\left(\frac{1}{\rho_{1}}-\frac{1}{\rho_{s}}\right), \ldots(2) \\
\therefore \rho & =\rho_{s}\left\{1-\left(\frac{1}{2}-q\right)\left(\rho_{s} / \rho_{1}-1\right)+\left(\frac{1}{2}-q\right)^{2}\left(\rho_{s} / \rho_{1}-1\right)^{2}+\ldots\right\},
\end{aligned}
$$

Now for $\mathbb{S}$ and 1 we shall bave approximately

$$
\begin{aligned}
& \rho_{s}={ }_{0} \rho_{s}\left(1-k_{s} t\right), \quad \rho_{1}={ }_{0} \rho_{1}\left(1-k_{1} t\right), \\
& \therefore \rho={ }_{0} \rho_{s}\left[1+\frac{1}{2}-\frac{1}{2} \frac{0 \rho_{s}}{{ }_{0} \rho_{1}}\left\{1+\left(3 \frac{0{ }_{0} \rho_{1}}{{ }_{0} \rho_{s}}-2\right) k_{s} t+k_{1} t\right\}\right. \\
& \left.+g\left\{\left(\frac{0 \rho_{s}}{{ }_{0} \rho_{1}}-1\right)\left(1-k_{s} t\right)-\frac{{ }^{o} \rho}{{ }_{0} \rho_{1}}\left(k_{s}-k_{1}\right) t\right\}+\ldots\right] \\
& ={ }_{o} \rho_{s}\left[1+\frac{1}{2}-\frac{{ }_{0} \rho_{s} / 2_{0} \rho_{1}}{1-t\left\{\left(3_{0} \rho_{1} / 0 \rho_{s}-2\right) k_{s}^{\prime}+k_{1}^{\prime}\right\}}\right. \\
& \left.+q\left\{\left(\frac{0 \rho_{s}}{{ }_{0} \rho_{1}}-1\right)\left(1-k_{s} t\right)-{\frac{o \rho_{s}}{{ }_{0} \rho_{1}}}_{1}\left(k_{s}-k_{1}\right) t\right\}\right], .
\end{aligned}
$$

where $k_{s}^{\prime}$ and $k_{1}^{\prime}$ ought to be nearly equal to $k_{s}$ and $k_{1}$ and are used to bring our expansion back to a form suitable for comparison with Mendeléeff's empirical equation in its form (A). In the sequel they will be taken as $k_{g}$ and $k_{1}$.

$A$ comparison of $(A)$ and $(B)$ gives

$$
\begin{aligned}
& { }_{\mathrm{o}} \rho_{s}=1, \text {. . . . . . } \\
& { }_{o} \rho_{8} / 2_{0} \rho_{1}=\cdot 45896 \quad \therefore{ }_{0} \rho_{1}=1 \cdot 08942, \quad \text {. . . . . } \\
& \left(3_{0} \rho_{1} /_{0} \rho_{s}-2\right) k_{s}+k_{1}=1 / 703 \cdot 51 \\
& \begin{aligned}
\therefore 02632-\frac{.067485}{1+t / 94 \cdot 1}=q\left({ }_{0} \rho_{s} / \rho_{1}-1\right)\left(1-k_{s} t\right)-t\left(k_{z}-k_{1}\right)_{o} \rho_{s} / o \rho_{1}
\end{aligned} \\
& =-\cdot 08208 q\left(1-k_{8} t\right)-\cdot 91792\left(k_{s}-k_{1}\right) t .(6)
\end{aligned}
$$


The value 1.08942 for ${ }_{0} \rho_{1}$ the density at zero of one of the pure ingredients agrees with the value indicated by the asymptote in the figure, and the law of dissociation of our standard mixture $S$ at different temperatures is given by (6), to which we shall return when we have determined the composition of our standard mixture. We shall neglect in it the small terms and write it

$$
q=\frac{\cdot 8222}{1+\cdot 010627 t}-\cdot 3207 . \quad . \quad . \quad .
$$

In this form it gives for $q=1 / 2, t=-\cdot 06^{\circ}$ instead of $4^{\circ}$ as the temperature at which the percentage of 1 added to $S$ is 0 ; this is the result of neglecting the small terms, and is of no importance in the study of $q$ at present. For $q=0$, that is for a mixture of equal parts of 1 and $\mathrm{S}, t=147$. The largest possible negative value of $q$ is when $t=\infty$ and is - $\cdot 32$, so that obviously the formula does not include in its range the case of $q=-1 / 2$, that is of the complete dissociation of water into the pure substance 1. Nor should the formula be expected to do so, as its empirical range is only to the boiling-point, though it may be used for purposes of approximation up to nearly 200 degrees.

To determine the composition of $\mathrm{S}$ we shall now consider another remarkable exceptional property of water, namely, its large expansion upon solidification. According to Bunsen unit volume of water at $0^{\circ}$ becomes 1.09082 of ice at $0^{\circ}$, and notwithstanding this considerable forcing apart of the molecules of water against their mutual attractions, for which we should expect that energy would have to be put into water to solidify it, we find actually that energy or heat has to be taken out of water to change it to ice. For comparison we can consider the expansion of metals and phosphorus when they melt. According to Vicentini and Omodei (Wied. Beibl. xii.) a volume 1000 of each of the following increase by

$\begin{array}{lllllll}\mathrm{Pb} . & \mathrm{Cd} . & \mathrm{Sn} . & \mathrm{Na} . & \mathrm{K} . & \mathrm{P} . & \mathrm{Hg} . \\ 34 & 47 & 28 & 25 & 26 & 35 & 37\end{array}$

Therefore there is on the average an expansion of such solids on melting by $3 \cdot 3$ per cent., whereas with water there is a contraction of $8 \cdot 3$ per cent. These facts alone are enough to suggest that the solidifying of water into ice is no mere physical change of state, as with most melting bodies, but is chiefly a profound chemical change. This view of the melting of ice will be gone into fully in sections $\tilde{5}$ and 8 , and in the meanwhile we shall assume that water in solidifying changes entirely into its other pure ingredient, which we $2 \mathrm{~K} 2$ 
shall denote by 2. This in its solid form as ice has a density .91662, and if it could expand without dissociation would probably expand like a melting metal by about 3 or 4 per cent., so that the density of our second pure ingredient as $\boldsymbol{x}$ liquid at 0 ought to be about $\cdot 88$. If, then, this is mixed with the pure ingredient $I$ having density 1.08942 to produce without shrinkage our standard mixture $S$ of density 1 (nearly). at 0 , it is easy to calculate what part $p_{2}$ of it by weight has to be mixed with $p_{1}=1-p_{2}$ of 1 by the equation

$$
\begin{aligned}
1 & =p_{2} / \cdot 88+\left(1-p_{2}\right) / 1 \cdot 089, \quad . \quad . \quad . \\
\therefore \text { at } 0, \quad p_{2} & =\cdot 375 \\
\text { and at } t, \quad p_{2} & =\cdot 375(1 / 2+q),
\end{aligned}
$$

because water at temperature $t$ contains $1 / 2+q$ parts of $\mathbf{S}$ in one part of water, and therefore it contains $\cdot 375(1 / 2+q)$ parts of 2 in one part of water, $q$ being $1 / 2$ almost at $0^{\circ}$. In the following table are given the fraction $p_{2}$ of ingredient 2 (trihydrol) in one part of water at different temperatures, the values of $g$ according to (7) being also included.

\begin{tabular}{cccccccccr}
\multicolumn{10}{c}{ TABLE I. } \\
$t \ldots$ & $0^{\circ}$ & $20^{\circ}$ & $40^{\circ}$ & $60^{\circ}$ & $80^{\circ}$ & $100^{\circ}$ & $120^{\circ}$ & $140^{\circ}$ & $198^{\circ}$ \\
$q \ldots$ & $\cdot 5$ & -357 & -256 & -181 & $\cdot 123$ & -087 & $\cdot 040$ & -010 & $-\cdot 061$ \\
$1000 p_{2} \ldots$ & 375 & 321 & 284 & 255 & 234 & 217 & 203 & 191 & 165
\end{tabular}

In using the formulæ to calculate values for $198^{\circ}$ we are extrapolating beyond their proper range, and must take such values as first approximations only. It is evident from these. numbers that at the critical temperature of water, which is about $368^{\circ} \mathrm{C}$, water must consist of nearly pure ingredient 1 which we shall prove in section 4 to be dihydrol. Now Thorpe and Rücker have furnished a convenient approximate relation between the coefficient of expansion of a liquid and its critical temperature (Journ. Chem. Soc. xliv.), namely,

$$
\frac{v_{0}}{v_{t}}=\frac{1.99 \mathrm{~T}_{c}-\mathrm{T}}{1.99 \mathrm{~T}_{c}-273}, \quad . . \cdot
$$

where $v_{0}$ and $v_{t}$ are volumes at $0^{\circ}$ and $t$ C., while $\mathrm{T}_{c}$ is the absolute critical temperature, which for dihydrol is 641 . Thus, then, for this liquid we have

$$
\frac{v_{0}}{v_{100}}=\cdot 900=1-100 k_{1}, \quad \therefore k_{1}=\cdot 001,
$$


which agrees with the value found graphically by means of the asymptote. Accordingly, from (5) we have $k_{s}=\cdot 00033$. thus

But $\mathrm{S}$ is a mixture of $\cdot 375$ parts of 2 and $\cdot 625$ of 1 , and

$$
\begin{aligned}
v & =\cdot 375 v_{2}+\cdot 625 v_{1} ; \\
\therefore \text { at } 0^{\circ} \quad \frac{d v}{d t} & =\cdot 375 k_{2} / \rho_{2}+\cdot 625 k_{1} / \rho_{1} . \quad \text {. . . }
\end{aligned}
$$

With $\cdot 00033$ as the value of $d v / d t$ at $0^{\circ}$, and the values of $\rho_{1},{ }_{0} \rho_{2}$, and $k_{1}$, this gives a negative value for $k_{2}$. This is undoubtedly wrong. One cause of the error may be that we have got too large a value of $k_{1}$ by Thorpe and Rücker's approximate formula; another cause may be that 1 and 2 do not mix without shrinking, as assumed in establishing (B), a very small change in the neglected shrinkage at different temperatures would modify considerably the meanings of $k_{1}$ and $k_{2}$ as they appear in (B), which has been forced into the form of Mendeléeff's empirical equation. Indeed our process of getting (B) into a form the same as (A) tends to make the separation of the true coefficients of expansion difficult. The following method of proceeding for $k_{1}$ and $k_{2}$ seems safer. According to Plücker and Geissler (Pogg. Ann. lxxxvi.) the coefficient of cubical expansion of ice is .000157 , and according to Hagen (Wied. Ann. xxxix.) the coefficients of $\mathrm{Na}$ and $\mathrm{K}$ on melting increase by ' 3 of their values; so by analogy we shall take the coefficient of liquid trihydrol to be about 0002 . With this in (11) and (5) we get $k_{1}=\cdot 00076$. I shall adopt - 0009 as a reasonable compromise for the value of $k_{1}$, retaining $\cdot 0002$ as the value of $k_{2}$. This seems small, but as I hope to show that the melting-point of ice is not the true physical melting-point of trihydrol, but its temperature of dissociation, we can take .0002 as the coefficient of trihydrol below its true melting-point, in solution in dibydrol ; the analogy just used with melting $\mathrm{Na}$ and $\mathrm{K}$ was intended to provide an allowance for increased molecular freedom in the liquid state, without implying that the melting of ice is a true physical melting like that of these metals.

\section{Confirmation from Optical Refraction.}

Before going farther it is important to confirm our conclusion that water is a mixture of liquids 1 and 2 in proportions given by Table I., and at the present stage an optical method is most appropriate. For a mixture of $p_{1}$ parts by weight of a liquid of refractive index $n_{1}$ with $p_{2}$ parts of a 
liquid of index $n_{2}$, we have its index $n$ given by the LorenzLorentz formula

$$
\begin{aligned}
\frac{1}{\rho} \frac{n^{2}-1}{n^{2}+2} & =\frac{p_{1}}{\rho_{1}} \frac{n_{1}{ }^{2}-1}{n_{1}^{2}+2}+\frac{p_{2}}{\rho_{2}} \frac{n_{2}{ }^{2}-1}{n_{2}{ }^{2}+2}, . . . . \\
& =\frac{1}{\rho_{1}} \frac{n_{1}{ }^{2}-1}{n_{1}^{2}+2}+p_{2}\left(\frac{1}{\rho_{2}} \frac{n_{2}{ }^{2}-1}{n_{2}^{2}+2}-\frac{1}{\rho_{1}} \frac{n_{1}{ }^{2}-1}{n_{1}{ }^{2}+2}\right),
\end{aligned}
$$

so that $\left(n^{2}-1\right) /\left(n^{2}+2\right) \rho$, say $R$, is a linear function of $p_{2}$; therefore we shall tabulate the values of this expression at different temperatures for water and the values of $p_{2}$ from Table I. side by side, and also the values of their respective successive differences denoted in the next table by $\Delta R$ and $\Delta p_{2}$. The indexes $n$ for water are those of Ketteler (Wied. Ann. xxxiii.) and for ice that of Pulfrich (Wied. Ann. xxxiv.), and the densities are the mean values given by Mendeléeff.

\section{TABLE II.}

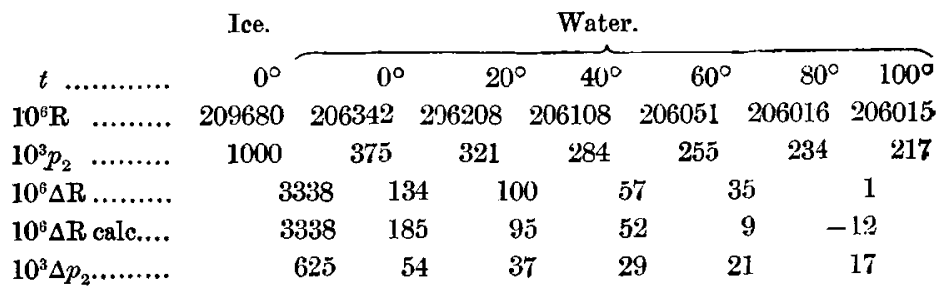

It will be noticed that the values of $\Delta\left(n^{2}-1\right) /\left(n^{2}+2\right) \rho$ and of $\Delta p_{2}$ run a similar course, but that the former tend to diminish to a 0 value more rapidly than the latter. This is connected with an interesting fact that water differs from ordinary liquids in showing a diminution of $\left(n^{2}-1\right) /\left(n^{2}+2\right) \rho$ with rising temperature, whereas it usually increases. Thus Lorenz (Wied. Ann. xi.) finds it to increase by the following number of parts in 10,000 for the following liquids from $10^{8}$ to $20^{\circ}$ :-ethyl oxide 8 , chloroform 4 , ethyl iodide 5 , othyl acetate 11 , carbon disulphide 12 . It appears, therefore, that in water this normal temperature effect of an increase has superposed on it a diminution due to the changing composition of water; the result being that in water $\left(n^{2}-1\right) /\left(n^{2}+2\right) \rho$ is nearly stationary at $80^{\circ}$ and $100^{\circ}$. In the case of water then $\Delta\left(n^{2}-1\right) /\left(n^{2}+2\right) \rho$ consists of two parts, one proportional to increase of temperature $\Delta t$ like those just given for ordinary liquids, and the other proportional to $\Delta p_{2}$, thus

$$
\Delta\left(n^{2}-1\right) /\left(n^{2}+2\right) \rho=\cdot 00000515 \Delta t+\cdot 00534 \Delta p_{2},
$$


$\Delta p_{2}$ being negativo when denoting a diminution. The values of $\Delta \mathrm{R}$ marked "calculated" in the last table are derived from the values of $\Delta p_{2}$ by this formula. Ketteler considers bis values of $n$ reliable to within a few units in the fifth decimal place, which iuplies that we should not have given the values of $10^{6} \mathrm{R}$ to more than five figures, and should not expect our values of $10^{6} \Delta R$, as calculated, to agree closer than within a few units in the tens place of digits with the found values, as the table shows to be actually the case. Thus for the two ingredients of water the temperature effect for $10^{\circ}$ seems to be an increase of about 2.5 parts in 10,000 , and with this taken into account the composition of water as determined optically is in agreement with that found from its expansion. For $\left(n^{2}-1\right) /\left(n^{2}+2\right) \rho$ for 2 (trihydrol) and 1 (dihydrol) we have by (13) the values

$\cdot 20968$ and $\cdot 20434$.

3. Compressitility of Water and Dissociation of Trityllol into I)ihydrol by Pressure.

One of the peculiarities of water is that its compressibility at low pressures diminishes with temperature to a minimum and then increases. Denoting volume of a gramme by $v$ we can write the mixture formula for volume

$$
v=p_{1} v_{1}+p_{2} v_{2}, \quad \text {. . . . . }
$$

and denoting pressure by $f$ we have

$$
\frac{d v}{d f^{*}}=p_{1} \frac{d v_{1}}{d f^{\prime}}+p_{2} \frac{d v_{2}}{d f^{j}}+\left(v_{2}-v_{1}\right) \frac{d p_{2}}{d f^{\circ}} \quad .
$$

In this equation we have $d v / d f$ from the experimental compressibilities of water at different temperatures, we know $p_{1}$ and $p_{2}$ from previous sections, and also $v_{2}-v_{1}$, but there remain three unknowns $d v_{1} / d f, d v_{2} / d f$, and $d p_{2} / d f$, and their variations with temperature are also unknown. To get farther it is necessary that we should estimate the compressibilities of our two ingredients. I propose to do this for 1 (dihydrol) in the following manner. In "The Laws of Molecular Force "(Phil. Mag. [5] xxxv.) I have shown that within a limited range of temperature and pressure the characteristic equation for liquids is such that

$$
v^{2} \mathrm{~T} \frac{d f^{\prime}}{d^{\prime} \mathrm{T}}=\frac{3}{4} l-{ }_{25}^{25} \mathrm{R} r \mathrm{~T}, \quad \text {. . . . }
$$

approximately, where $l$ is the virial constent or parameter of 
the substance, and $\mathbf{R}$ the usual constant for it when a perfect gas, $\mathbf{T}$ the absolute temperature. Thanks to Amagat's invaluable supply of data (Ann. de Ch. et de Phys. [6] xxix.), I have been able to find an equation of more extensive range, but as this is still in manuscript, I shall use here the published equation referred to. In that paper, p. 276, values of $\mathbf{M}^{2} l$ for water are given, $\mathbf{M}$ being the molecular mass which for $\mathrm{H}_{2} \mathrm{O}$ is 18 . With the dyne as unit of force these are $11 \times 10^{12}$ from the latent heat of vaporization, $9 \times 10^{12}$ from the critical data, and $6 \times 10^{12}$ from the capillary data. The last value was obtained on the assumption that in water the molecules consist of $\left(\mathrm{H}_{2} \mathrm{O}\right)_{2}$, but $\mathrm{M}$ in $\mathrm{M}^{2} l$ is only 18 . As the latent heat of vaporization of water includes also the heat of dissociation of its complex molecules, and as the critical pressure probably has its value seriously affected by dissociation, the value $6 \times 10^{12}$ must be the most nearly correct, as I have hitherto always treated it to be. Then changing to the atmo as the unit of pressure, when $\mathrm{RT}$ at $0^{\circ} \mathrm{C}$. bas the value $11200 / 9$, we get for $\left(\mathrm{H}_{2} \mathrm{O}\right)_{2}$ or 1 at $0^{\circ}$

$$
v^{2} \mathrm{~T} \frac{d f}{d \mathrm{~T}}=12790
$$

but as

$$
\frac{d f}{d \mathrm{~T}}=-\frac{d v}{d \mathrm{~T}} \mid \frac{d v}{d f}, \quad \therefore \frac{1}{v} \frac{d v}{d f}=-\frac{1}{v} \frac{d v}{d \mathrm{~T}} / \frac{d f}{d \mathrm{~T}}=k \rho_{0} / \rho \frac{d f}{d \mathrm{~T}},
$$

using the value of $k_{1}$, namely $\cdot 0009$, we have for the calculated compressibility of 1 at $0^{\circ}$ the value $\cdot 000016$. Similarly at $50^{\circ}$ we get 0000235 . For higher temperatures it seems to me safest to proceed thus. According to van der Waals's principle of correspondence, the compressibilities of 1 and of etbyl oxide at low pressures will always be in the same ratio to one another if taken for comparison at temperatures which are equal fractions of their absolute critical temperatures. We may take the absolute critical temperature of 1 as the same as that of water, namely 641 , and that of ethyl oxide as 468 . In the next table are given certain temperatures $\mathrm{C}$ for 1 and the temperatures $\mathrm{C}$ for ethyl oxide which correspond to these ; then the compressibilities of ethyl oxide at these temperatures, and finally the compressibilities of 1 (dihydrol) calculated from those for ethyl oxide on the principle that the ratio at all the corresponding temperatures is that which holds for 1 at $50^{\circ}$ and ethyl oxide at $-37^{\circ}$, obtained by extrapolation from Amagat's data from $0^{\circ}$ to $200^{\circ}$ between 50 and 100 atmos. 


$\begin{array}{lcccccc}\text { Temp. of } 1 \ldots \ldots \ldots \ldots \ldots \ldots \ldots & 198^{\circ} & 100^{\circ} & 90^{\circ} & 50^{\circ} & 0^{\circ} \\ \text { Temp. of ethyl oxide } \ldots \ldots \ldots \ldots . & 71 & -1 & -8 & -37 & \\ \text { Compr. of ethyl oxide } \times 10^{5} \ldots . . & 28 & 13 & 10 \cdot 5 & 8 & \\ \text { Compr. of } 1 \ldots \ldots \ldots \times 10^{6} \ldots & 82 & 38 & 31 & 23.5 & 16\end{array}$

In equation (15) we can use Amagat's values of the compressibility of water to give $d v / d f$, as in the next table; from the last table wo derive $d v_{1} d f$, and from Table I. $p_{1}$, and thus get the values of $p_{2} d v_{2}^{\prime} d f+\left(v_{2}-v_{1}\right) d p_{2} / d f$ given in the last line of the next table.

TABLe III.

$\begin{array}{lrrrl}\text { Temp. C. ........................... } & 0^{\circ} & 50^{\circ} & 100^{\circ} & 198^{\circ} \\ 10^{7} d v / v d f \text { for water................. } & 492 & 425 & 468 & 800 \\ 10^{7} d v / d f \text { for water .................. } & 492 & 430 & 488 & 928 \\ 10^{7} p_{1} d v_{1} / d f \ldots \ldots \ldots \ldots \ldots \ldots \ldots \ldots \ldots . . & 93 & 165 & 301 & 769 \\ 10^{7}\left\{p_{2} d v_{2} / d f+\left(v_{2}-v_{1}\right) d p_{2} / d f\right\} \ldots & 399 & 265 & 187 & 159\end{array}$

It should be noticed that the compressibility we have calculated for 1 at $198^{\circ}$ is nearly the same as that found by Amagat for water at $198^{\circ}$, at which temperature it ought to be nearly all 1 ; this, therefore, confirms our calculated compressibilities for 1 . The numbers of the last row are made up of two parts, $p_{2} d v_{2} / d f$ and $\left(v_{2}-v_{1}\right) d p_{2} / d f$. Now $p_{2}$ has a vilue, $\cdot 375$ at $0^{\circ}$, which falls to $\cdot 217$ at $100^{\circ}$, so that these numbers may be said to include on the average about $\frac{1}{3}$ of $d v_{2} / d f$ for 2 . But for a substance so near its solidifyingpoint as 2 is at these temperatures, 00001 would be a reasonable allowance for $d v_{2} / d f$ at $0^{\circ}$, and as $d v_{2} / d f$ increases while $p_{2}$ diminishes with rising temperature, 000003 may be used as an approximate value of $p_{2} d v_{2} d d f$, at all temperatures up to $100^{\circ}$. As we now can calculate $v_{2}$ and $v_{1}$ at all temperatures, we have $v_{2}-v_{1}$ as given in the next table, and therefore $d p_{2} / d f$ given in the last row.

\begin{tabular}{rrrr} 
TABLE IV. \\
\multicolumn{5}{c}{$0^{\circ}$} & $50^{\circ}$ & $100^{\circ}$ \\
$-10^{7}\left(v_{2}-v_{1}\right) d p_{2} / d f \ldots \ldots \ldots \ldots$ & 369 & 235 & 157 \\
$10^{1}\left(v_{2}-v_{1}\right) \ldots \ldots \ldots \ldots \ldots \ldots$. & 2185 & 1869 & 1509 \\
$-10^{8} d p_{2} / d f \ldots \ldots \ldots \ldots \ldots \ldots$. & 170 & 126 & 104
\end{tabular}

We have thus obtained estimates of the rate at which a gramme of 2 (trihydrol) is dissociated by pressure at different temperatures, namely, 00017 gramme per atmo at $0^{\circ}$ and .0001 gramme per atmo at $100^{\circ}$. 
We can study this dissociation from a slightly different point of view. Amagat's data (Ann. de Ch. et de Ph. [6] xxix.) enable us to assign the temperature of maximum density of water under 150 atmos as $55^{\circ}$. Althongh his pressures go up to 3000 atmos the maximum density has not been ascertained by him at a higher pressure than 150 atmos. Accordingly I have found the equation like Mendelefeff's which will represent the expansion of water under 150 atmos. With the volume of a gramme of water at $4^{\circ}$ and under 1 atmo as unity it is

$\rho=1 \cdot 00747\left(1+\cdot 76354-\frac{.087724}{1+\cdot 008375 t}-\frac{\cdot 67584}{1-.001077 t}\right)$.

The volumes of a gramme of water as given by this formula and by Amagat, when we have changed his unit of volume to that just mentioned, are :-

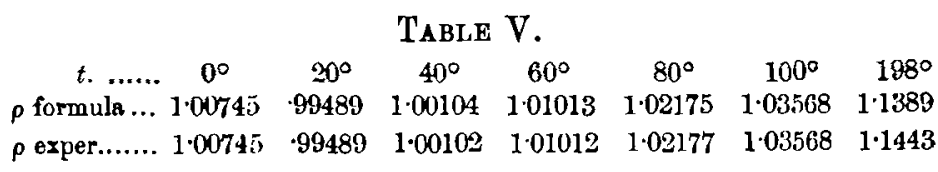

$\mathrm{Up}$ to $100^{\circ}$ the equation represents the actual data with a maximum error of 2 parts in 100,000 , the comparison for $198^{\circ}$ being added to show how far the form fails when applied much beyond the ordinary boiling-point.

On comparing this last equation with Mendeléeft's for one atmo (A) and with (B), we see how the terms expressing expansion of the two ingredients and dissociation bave got mixed up; a result always to be feared with empirical equaltions, which fact indeed makes it appear a happy accident that Mendeléeff"s formula (A) is capable of such easy interpretation. We have now to disentangle the mixed up parts of the last equation. It relates to $p$ of 1 mixed with $1-p$ parts of a mixture which we shall denote by $S^{\prime}$ (different from $S$ ). The density of $S^{\prime}$ is 1.00747 , and therefore its volume is .99259 , and the volume of 1 (dihydrol) as a liquill, being $1 / 1 \cdot 08942$ at $0^{\circ}$ under 1 atmo, is 91572 under 150 atmos when the compressibility .000016 is taken into account. Now $\mathrm{S}^{\prime}$ also contains 2 under 150 atmos; under 1 atmo at 0 it was taken to have a volume $1 / .88$, and the compressibility -00001 was conceded to it, so that its volume at $0^{\circ}$ under 150 atmos is $1 \cdot 13466$; and applying the mixture formula to the density of $\mathrm{S}^{\prime}$ we have

$$
\begin{aligned}
\cdot 99259 & =\cdot 91572+(1 \cdot 13466-\cdot 91572) p_{2}, \\
\therefore p_{2} & =\cdot 351 \text { at } 0^{\circ} \text { under } 150 \text { atmos. . . . }
\end{aligned}
$$


Under one atmo we found $p_{9}=\cdot 375$ at $0^{\circ}$, so that at this temperature $d p_{2} / d f=\cdot 024 / 149=\cdot 00016$, in fair agreement, as it ought of necessity to be, with the value found from comprossibilities, namely, $\cdot 00017$.

In order to disentangke the dissociation terms of (C) from the expansion terms, we must make the dissociation produced by pressure at the different temperatures run a similin course to that in Table IV. A little arithmetic leads to

$$
\begin{gathered}
\cdot 07744 q=\frac{\cdot 087724}{1+\cdot 008375 t}+\frac{\cdot 05398}{1-\cdot 001077 t}-\cdot 10298 . \\
\frac{\cdot 46128}{1-t\left(1 \cdot 252 k_{s}^{*}+k_{1}\right)}=\frac{\cdot 62186}{1-\cdot 001077 t}-\cdot 16056 .
\end{gathered}
$$

In one gramme of water the amount of 2 (trilydrol) at any temperature being $351(1 / 2+1)$, we have the following amounts of 2 under 150 atmos for comparison with those under 1 atmo.

\begin{tabular}{rrrrrrrr}
\multicolumn{8}{c}{ TABLE VI. } \\
$t \ldots \ldots \ldots \ldots \ldots \ldots . \ldots$ & $0^{\circ}$ & $20^{\circ}$ & $40^{\circ}$ & $60^{\circ}$ & $80^{\circ}$ & $100^{\circ}$ \\
$10^{3} p_{2}(150$ atmos $) \ldots \ldots$. & 351 & 300 & 264 & 237 & 217 & 203 \\
$10^{3} p_{2}(1$ atmo $) \ldots \ldots \ldots$. & 375 & 321 & 284 & 255 & 234 & 217 \\
$10^{3} \Delta p_{2}$ & $\ldots \ldots \ldots \ldots \ldots \ldots$ & 24 & 21 & 20 & 18 & 17 & 14
\end{tabular}

Smoothing these last differences and dividing them by 150, we get:-

\begin{tabular}{rrrrrrr}
\multicolumn{7}{c}{ TABLE VII. } \\
$10^{3} \Delta p_{2} \ldots \ldots \ldots \ldots \ldots \ldots$ & 24 & 22 & 20 & 18 & 16 & 14 \\
$-10^{8} d p_{2} / d f \ldots \ldots \ldots \ldots \ldots$. & 160 & 147 & 133 & 120 & 107 & 93
\end{tabular}

If the values just found for $d p_{2} / d f$ hold up to prosures at which the whole of 2 is dissociated, it appeatrs that at $\cdot 375 / \cdot 00016$ or about 2300 atmos the whole of the 2 (trihydrol) will be dissociated at $0^{\circ}$; at $100^{\circ}$ the pressure of complete dissociation would be $217 / 000093$, also ahout 2300 atmos. These results agree well with Amagat's conclusion that at high pressures, even below 3000 atmos, the irregularities of water disappear; water becomes an ordinary liquid, that is to say, the mixture of 2 and 1 has been converted into pure compressed 1.

The effect of pressure in dissociating 2 has an important bearing on the composition of the surface-film of water. If pressure causes dissociation, tension may be expected to prodnce association, and therefore we may expect the proportion 
of 2 to be higher in the surface than in the body of water. This will now be discussed in the next section.

\section{Surface-tension and Constitution of Water in Surface-film.}

The relation which I have shown to exist between the surface-tension $\alpha$ of a mixture and those of its ingredients (Phil. Mag. [5] xxxviii., xl.) is approximately

$$
\begin{gathered}
\alpha^{\frac{1}{2}} / \rho=p_{1} \alpha_{1}^{\frac{1}{2}} / \rho_{1}+p_{2} \alpha_{2}^{\frac{1}{2}} / \rho_{2}, \quad . . . \\
\text { and } 1 / \rho=p_{1} / \rho_{1}+p_{2} / \rho_{2} \text { if there is no shrinkage, } \\
\therefore\left(\alpha_{2}^{\frac{1}{3}}-\alpha^{\frac{1}{2}}\right) / \rho_{2}+p_{1}\left\{\left(\alpha_{1}^{\frac{1}{2}}-\alpha_{2}^{\frac{1}{2}}\right) / \rho_{1}-\left(\alpha_{2^{\frac{1}{2}}}-\alpha^{\frac{1}{3}}\right) / \rho_{2}\right\}=0 .
\end{gathered}
$$

We have also Eötvös's discovery (Wied. Ann. xxvii.) that, $\mathbf{M} v$ being the volume of a gramme molecule and $\alpha(\mathbf{M} v)^{\frac{2}{3}}$ the molecular surface-tension $\sigma$, then $d \sigma / d t$ is nearly the same for all normal liquids, and retains a nearly constant value up to near the critical temperature, while for associated liquids of varying degree of association it is not constant. With the dyne as unit of force Ramsay and his pupils have found a mean value $2 \cdot 121$ for Eötvös's constant $d \sigma / d t$. Ramsay's values of $\alpha(\mathbf{M} v)^{\frac{2}{3}}$ or $\sigma$ with $M=18$ for water (Proc. Roy. Soc. lvi. p. 177) are given in the next table with a value 0 inserted for the critical temperature and below them the values of $100 \Delta \sigma / \Delta t$.

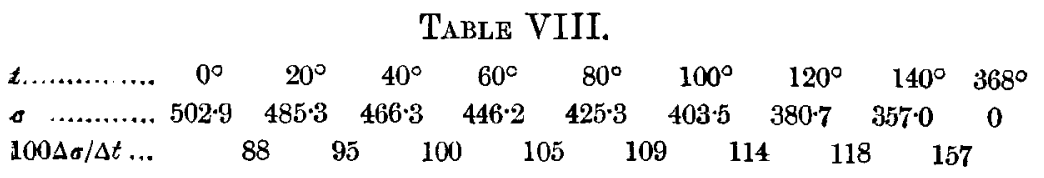

These values of $\Delta \sigma / \Delta t$ show no tendency towards becoming stationary at near $0^{\circ}$, but let us take $\cdot 92$ as the order of their magnitude near $0^{\circ}$. This when multiplied by $3^{\frac{2}{3}}$ vields $1 \cdot 91$, which is near enough to the $2 \cdot 121$ of a normal liquid to suggest that the surface-film of water at $0^{\circ}$ consists of $\left(\mathrm{H}_{2} \mathrm{O}\right)_{3}$. But if this is so we should also multiply by $(1 / \cdot 88)^{\frac{2}{3}}$, where $\cdot 88$ is the density of our ingredient 2, and this brings 1.91 up to $2 \cdot 08$, which is still nearer the result for an average liquid. There is, therefore, fair evidence that the tension in the surface-layer of water at $0^{\circ}$ is sufficient to cause practically the whole of the water there to change into trihydrol, whose surface-tension is that of water at $0^{\circ}$, namely, 73.32 dynes per centim., and then by Eiötvös's relation the surface-tension of trihydrol at any other temperature is given 
by the equation

$$
\alpha_{2}\left(54 / \rho_{2}\right)^{\frac{2}{3}}=73 \cdot 32(54 / \cdot 88)^{\frac{2}{3}}-2 \cdot 121 t . \quad .
$$

With it we calculate the values of $\alpha_{2}^{\frac{1}{2}}$ in the next table, also tabulating Ramsay's values for $\alpha^{\frac{1}{2}}$ and obtaining $\left(\alpha_{2^{\frac{1}{2}}}-\alpha^{\frac{1}{2}}\right) / \rho_{2}$.

TABLE IX.

\begin{tabular}{|c|c|c|c|c|c|c|c|c|}
\hline & $0^{\circ}$ & $20^{\circ}$ & $40^{\circ}$ & $60^{\circ}$ & $80^{\circ}$ & $100^{\circ}$ & $120^{\circ}$ & $140^{\circ}$ \\
\hline$a_{2}^{\frac{1}{2}}$ & 8.563 & $8 \cdot 395$ & $8 \cdot 217$ & 8.011 & $7 \cdot 858$ & $7 \cdot 675$ & $7 \cdot 489$ & 2 \\
\hline & 8.563 & $8 \cdot 400$ & $8 \cdot 219$ & $8 \cdot 017$ & 7.797 & $7 \cdot 5556$ & $7 \cdot 301$ & \\
\hline$\left(a_{2}^{\frac{2}{2}}\right.$ & 0 & 0 & 0 & $\cdot 028$ & .070 & $\cdot 138$ & & \\
\hline
\end{tabular}

It appears from this table that up to $40^{\circ}$ the surface-film of water consists of pure trihydrol $\left(\mathrm{H}_{2} \mathrm{O}\right)_{3}$, but that at $60^{\circ}$ and higher temperatures the surface-tension is so much reduced as to allow some of liquid 1 to form. Now at $40^{\circ}$ the surface-tension is 67.56 dynes per centim., and in the bodywater the amount of 1 per gramme is 716 , and the value of $d p_{1} / d f$ at $40^{\circ}$ is $\cdot 000133$, and therefore the tension per square centim. required to convert this amount of 1 into trihydrol will be $\cdot 716 / \cdot 000133$ or 5380 atmos. Therefore the thickness of the surface-film (defined below) is

$$
67 \cdot 56 / 538 \times 10^{7}=12 \cdot 6 \times 10^{-9} \text { centim. }
$$

Now Kelvin's estimate of the order of magnitude of ordinary molecular diameters is $2 \times 10^{-9}$ centim., so that our surface-film would be only a few molecules thick. This agrees with what I have suggested as to the thickness of the surface-film according to the law of the inverse fourth power for molecular attraction. Of course with such a law of force it is impossible that there can be any natural boundary between surface-film and body of fluid, and it is obvious that the tension must be greatest in the first layer of molecules on the surface; in the tenth layer we can imagine the attractions of the eleventh to the eighteenth equilibrating those of the first nine, and the dissymmetry causing tension in our tenth layer is only that due to a mass which begins at nine times the molecular diameter away; the effect of this must be very small compared to the effect of dissymmetry in the condition of the first layer. The thickness of the surfacefilm $\mathrm{D}$ can be most rationally defined as twice the distance of the centre of tension from the surface, in symbols

$$
\mathrm{D} \int f d l=2 \int f l d l \text {, }
$$

where $f$ is tension per unit area at depth $l$ from the surface. 
The average tension per square centim. of the film $\bar{f}=\alpha / D$. Above we have found $\bar{f}=5380$ atmos and

$$
\mathrm{D}=12.6 \times 10^{-9} \text { centim. }
$$

We can now calculate $p_{1}$ in equation (21), that is the amount of 1 in one gramme of the surface-film. For if we divide the surface-tensions of water at different temperatures by $12.6 \times 10^{-9}$, we get the average tensions per unit area in the surface-film as given in the table below. But if we divide the values of $p_{1}$, derived from those of $p_{2}$ in Table I., by the values of $d p_{2} / d f$ at the same temperatures from Table VII., we get the tension required to convert all of 1 in the body of the water into trihydrol in the surface-film. The difference between the former tension and the latter, expressed as a fraction of the latter, gives that fraction of $p_{1}$ which has not been converted into trihydrol, so that if we multiply this fraction by $p_{1}$ for the body of the liquid, we get $p_{1}$ for the surfacefilm as required in equation (21), and as given in the next table along with the derived values of $\boldsymbol{\alpha}_{1}$.

\begin{tabular}{cccc}
\multicolumn{4}{c}{ TABLE X. } \\
$t \ldots \ldots \ldots \ldots \ldots \ldots$ & $60^{\circ}$ & $80^{\circ}$ & $100^{\circ}$ \\
$a \ldots \ldots \ldots \ldots \ldots \ldots .$. & $64 \cdot 25$ & $60 \cdot 77$ & $57 \cdot 11$ dynes \\
$p_{1} \div d p_{1} / d f \ldots \ldots \ldots$ & 6210 & 7160 & 8420 atmos \\
$\ldots \ldots \ldots \ldots \ldots \ldots \ldots \ldots$ & 5120 & 4840 & 4550 atmos \\
$10^{3} p_{1}$ in surface... & 131 & 248 & 360 \\
$a_{1} \ldots \ldots \ldots \ldots \ldots \ldots$. & $61 \cdot 28$ & $57 \cdot 48$ & $53 \cdot 48$ dynes \\
$a_{1}\left(18 / \rho_{1}\right)^{\frac{2}{3}} \ldots \ldots \ldots .$. & $429 \cdot 3$ & $397 \cdot 6$ & $365 \cdot 2$ \\
$a_{1}\left(36 / \rho_{1}\right)^{\frac{2}{2}} \ldots \ldots \ldots$. & $681 \cdot 4$ & $631 \cdot 0$ & $579 \cdot 6$
\end{tabular}

The values of $d \alpha_{1}\left(18 / \rho_{1}\right)^{\frac{2}{3}} / d t$ between $60^{\circ}$ and $80^{\circ}$ and between $80^{\circ}$ and $100^{\circ}$ are 1.585 and 1.62 , mean 1.60 ; while for $d \alpha_{1}\left(36 / \rho_{1}\right)^{\frac{2}{3}} / d t$ the values are $2 \cdot 52$ and $2 \cdot 57$, mean $2 \cdot 54$. These are about equally different from 2.121 for an average liquid ; but we can more satisfactorily test whether 18 or 36 is the molecular mass of our ingredient 1 by assuming that the critical temperature of water $368^{\circ} \mathrm{C}$. is that of 1 , and therefore $\alpha_{1}\left(18 / \rho_{1}\right)^{\frac{3}{3}}$ and $\alpha_{1}\left(36 / \rho_{1}\right)^{\frac{2}{3}}$ must both vanish at about $368^{\circ}$; so that on dividing their values tabulated above by 308,288 , and 268 respectively, we should get much more reliable values of the appropriate coefficients. In this way for $a_{1}\left(36 / \rho_{1}\right)^{\frac{3}{3}}$ we get the temperature-coefficients $2 \cdot 21,2 \cdot 19$, and $2 \cdot 16$, mean $2 \cdot 19$, whereas the mean for the similar co- 
etficient of $\alpha_{1}\left(18 / \rho_{2}\right)^{\frac{3}{3}}$ is 1.38 . This, then, is decisive, and furnishes our proof that the liquid 1 is dihydrol.

The exceptional properties of the surface-tension of solutions have been discussed in "Molecular Force and the Surfacetension of Solutions" (Phil. Mag. [5] xl.), and it is now evident that they must be largely due to the difference between the surface-layer and the body of water, and to a possible action of the solute in dissociating some of the trihydrol. The solubility of substances in trihydrol may be different from that in water. A re-examination of the surfacetension of solutions would be full of interest.

\section{Latent Heat of Fusion, Specific Heat and Latent Heat of Evaporation.}

According to what precedes, ice is pure trihydrol. The crystallization of water in the hexagonal system is strong confirmation of this ; throughout the enormous variety of forms of ice-flowers the angle of $60^{\circ}$ is the dominant factor, and in the theory of halos the ice-crystals of the higher atmosphere appear as necessarily hexagonal prisms. All this points strongly to a decided three-directional symmetry in the molecule of ice to which we shall return in section 8 .

Meanwhile we must regard the latent heat of fusion of ice as no ordinary physical latent heat of fusion, for the melting of ice is accompanied by the conversion of 625 of its trihydrol into dihydrol; the latent heat of fusion must be mainly a chemical latent heat of dissociation. It is evident that this must be so, because ice in melting contracts by one-ninth; and if there were no dissociation involved ought to show a latent cold and not a latent heat of fusion. We can calculate what the true physical heat of fusion of solid trihydrol into liquid trihydrol ought to be approximately. In section 3 we took the virial constant for dihydrol to be $1852 \times 10^{7}$ with the dyne as unit of force ; and according to the laws of molecular force the value for trihydrol must be nearly the same, as we shall see it to be in a subsequent calculation in this section. If $\rho_{2}{ }^{\prime}$ and $\rho_{2}$ are the densities of solid and liquid trihydrol at $0^{\circ}$, then its true heat of fusion in ergs should be $l\left(\rho_{\Omega}^{\prime}-\rho_{2}\right)$, nearly. But $\rho_{2}^{\prime}-\rho_{2}$ has been taken as 0366 , and therefore the true heat of fusion in calories of trihydrol expanding on fusion would be $1852 \times 10 \times \cdot 0366 / 42=16$ calories. The greater part then of the 80 calories that go to the fusion of a gramme of ico must be used to dissociate 625 gramme of trihydrol into dihydrol and dissolve the remaining .375 gramme in 625 gramme of dihydrol. 
Before going further we must consider the specific heat of water. In this property water again shows its very exceptional character; not only is the specific heat much larger than would be expected by analogy, but it is remarkably nearly constant over a large range of temperature. Evidently we bave to do, not with a true physical specific heat, but with a very complicated thermal phenomenon involving dissociation. To unravel this we must make estimates of the specific heats of trihydrol and dihydrol. According to Kopp's rule the molecular specific beat of $\mathrm{H}_{2} \mathrm{O}$ ought to be made up of $2 \cdot 3 \times 2$ for the bydrogen, and 4 for the oxygen, that is 8.6 ; and therefore the specific heat ought to be $86 / 18=\cdot 48$, which is near to the 504 for ice, but not to the 1.0 for water. According to Kopp's rule the specific heat of tribydrol onght also to be 448 , unless some provision has to be made for the binding of three $\mathrm{H}_{2} \mathrm{O}$ molecules into one, although all analogy indicates that it would be slight. Thus ice regarded as a polymeric form of $\mathrm{H}_{2} \mathrm{O}$ uncomplicated by dissociation has a latent heat in accordance with Kopp's rule, and by contrast the large specific heat of water appears to be due to consumption of heat in causing dissociation. On examining the available data I find that substances on melting show an increase of specific heat varying from 20 to 50 per cent., with an average of about 25 ; and therefore we should expect pure liquid trihydrol at $0^{\circ}$ to have a specific heat about -625 . Now we know from Regnault's determinations that even up to $190^{\circ}$ the specifie heat of water increases but little; and wo therefore conclude that at $200^{\circ}$, when most of the trihydrol has been dissociated and the dissociation heat is of small account, the specific heat of the tolerably pure dihydrol is $1 \cdot 0$. As the usual rate of variation of the specific beat of liquids is about 1 per cent. per degree, we may infer that pure dihydrol at 0 would have a specitic heat about $\cdot 83$. This result seems to involve a large violation of Kopp's rule, according to which polymeric forms of $\mathrm{H}_{2} \mathrm{O}$ ought to have a specific heat near $\cdot 48$. But the great difference in the densities of trihydrol and dihydrol at 0 makes it probable that there is a decided difference in their specific heats at $0^{\circ}$. As the best estimates that we can make at present, let us write for the specific heats

$$
\begin{aligned}
& c_{1}=\cdot 6(1+\cdot 001 t), \quad . \quad . \quad . \quad . \\
& c_{2}=\cdot 8(1+\cdot 001 t), \quad . \quad .
\end{aligned}
$$

In the heating of a gramme of water we have to supply heat to raise the temperature of $p_{1}$ parts of dihydrol and of $p_{2}$ parts of trihydrol, and also heat to dissociate some trihydrol 
into dihydrol, and also the heat to effect the solution of the dissociated trihydrol. Let $h$ be the heat absorbed when $p_{1}$ gramme of dihydrol is mixed with $p_{2}=1-p_{1}$ gramme of liquid trihydrol, and $\mathrm{D}$ the heat absorbed in dissociating a gramme of trihydrol into dihydrol, then for the heat $d \mathrm{Q}$ to raise the temperature of a gramme of water by $d t$ we have

$$
\begin{aligned}
d \mathrm{Q} & =\left(p_{1} c_{1}+p_{2} c_{2}\right) d t+\left(\mathrm{D}+d h / d p_{2}\right) d p_{2} ; \\
\therefore \quad c & =\frac{d \mathrm{Q}}{d t} p_{1} c_{1}+p_{2} c_{2}+\left(\mathrm{D}+d h / d p_{2}\right) \frac{d p_{2}}{d t} . . .
\end{aligned}
$$

Now $c$ the specific heat of water can be taken as constant at $1 \cdot 0$, while $e_{1}$ and $e_{2}$ are known from $(23),(21)$, with $d p_{2} / d t$ from (7); so that the last equation furnishes us with values of $\mathrm{D}+d h / d p_{2}$, as given in the next table, where they are compared with those of $78+3290\left(\cdot 425-p_{2}\right)^{2}$ given in the last row.

$$
\begin{array}{cccccccc}
\multicolumn{10}{c}{\text { TABLE XI. }} \\
\text { t..... } 0^{\circ} & 20^{\circ} & 40^{\circ} & 60^{\circ} & 80^{\circ} & 100^{\circ} & 120^{\circ} & 140^{\circ} \\
86 & 114 & 142 & 172 & 200 & 223 & 241 & 2555 \\
86 & 114 & 143 & 173 & 198 & 220 & 240 & 258
\end{array}
$$

It appears from this that

$$
\begin{gathered}
-\mathrm{D}-\frac{d h}{d p_{z}}=78+3290\left(\cdot 425-p_{2}\right)^{2} ; \quad . \quad . \\
\therefore \quad-\mathrm{D} p_{2}-h=78 p_{2}-3290\left(\cdot 425-p_{2}\right)^{3} / 3+\mathrm{C} ;
\end{gathered}
$$

and as $h=0$ when $p_{2}=0$,

$$
\mathrm{C}=84 \cdot 2 \text {. }
$$

Then at $0^{\circ}$ with $p_{2}=\cdot 375$ we have

$$
-375 \mathrm{D}-h=113
$$

and from the latent heat of fusion of ice we have

$$
\begin{aligned}
& -625 \mathrm{D}+h=64 \text {; } \\
& \therefore \mathrm{D}=-177, \text {. . . . . . . . . . . } \\
& -h=-99 p_{2}-3290\left(\cdot 425-p_{2}\right)^{3} / 3+84 \cdot 2 . .
\end{aligned}
$$

The negative sign of $\mathrm{D}$ is the result of $d p_{2}$ in (25) being negative ; 177 calories have to be given per gramme of trihydrol to change it to dihydrol. This (28) then is the expression for the law of the evolution of heat when liquid trihydrol is dissolved in dihydrol up to a concentration of $\cdot 425$ trihydrol per gramme.

As water consists mostly of dihydrol while steam is hydrol, it follows that the latent heat of evaporation of water is not

Phil. Mag. S. 5. Vol. 50. No. 306. Nov. 1900. $2 \mathrm{~L}$ 
a true physical latent heat of evinoration, but includes the heat of dissociation. We proceed to calculate the hent of dissociation of dibydrol into hydrol and the true latent heat of dihydrol.

If we take 368 as the critical temperature of dibydrol, then at $\frac{2}{3}$ of the absolute critical temperature, that is at $155^{\circ} \mathrm{C}$., the gramme-molecular surface-tension of dihydrol must be about $2 \cdot 121(368-155)$ or 452 . Now according to the fifth method of finding the virial constant $l$ for a substance ("Laws of Molecular Force," Phil. Mag. [5] xxxv. p. 258),

$$
l=c \alpha v^{\frac{5}{3}} / \mathrm{M}^{\frac{l}{3}} \text {, }
$$

where $c=1209$ when $l$ is measured in terms of the megadyne and $\alpha$ of the dyne; for dihydrol

$$
\begin{aligned}
l & =1209 \times 452 \times v / \mathrm{M}, \\
v & =1 / 1 \cdot 08942(1-\cdot 0009 \times 155), \quad \mathrm{M}=36 ; \\
\therefore \quad l & =16192 .
\end{aligned}
$$

The equation of the third method of finding $l$ (ibid., p. 245) is

$$
l / v=66 \cdot 5 \lambda-101 \mathrm{~T}_{b} / \mathrm{M}, \quad . \quad . \quad .
$$

where $T_{b}$ is the boiling-point (absolute), $\lambda$ the latent heat of evaporation, and $v$ the volume of a gramme of the liquid at the boiling-point. Now $\lambda$ does not vary rapidly with the temperature, so we shall make but little error in taking $100^{\circ}$ as the boiling-point of dihydrol ; then

$$
\begin{aligned}
\mathrm{T}_{b} & =373, \quad \mathrm{M}=36, \quad v=1 \cdot 009 ; \\
\therefore \quad \lambda & =257 \text { calories. . . . . . . . }
\end{aligned}
$$

But the latent heat of water at $100^{\circ}$ is 537 , and jo the hent of evaporation of a solution of 217 gramme of tribydrol in .783 of dihydrol, and of the dissociation of hoth into hydrol.

Now the removal from solution of the 217 gramme of trihydrol would require by (28) $52 \cdot 8$ calories, and its dissociation into dihydrol by (27) 38.4 ; so that to convert a gramme of water at $100^{\circ}$ into pure dihydrol requires altogether 91.2 ; and therefore for the evaporation of a gramme of dihydrol and its dissociation into hydrol $537-91$ calories are required; and therefore the heat of dissociation of a gramme of dihydrol into hydrol is $446-257$ or 189 calories.

We can partly check this result by the following reasoning. To dissociate a gramme of trihydrol into hydrol via. 
dihydrol will require $177+189$ or 366 calories, and for the solid trihydrol 382 ; the usual so-called latent heat of evaporation of ice is about 660 ; and thus the latent heat of evaporation of liquid trihydrol, if evaporated without dissociation, would be 278 calories; of solid trihydrol 294.

The latent heat of evaporation of tribydrol at its boilingpoint can be estimated in exactly the same way as that of dihydrol. As $\alpha_{2}\left(54 / \rho_{2}\right)^{\frac{2}{3}}$ at $0^{\circ}$ is 1141 , and diminishes $2 \cdot 121$ per degree till it is zero at the critical temperature, the critical temperature of trihydrol is $538^{\circ} \mathrm{C}$.; therefore at $\frac{p}{3}$ of the absolute critical temperature $\alpha_{2}\left(54 / \rho_{2}\right)^{\frac{2}{3}}$ is $271 \times 2 \cdot 121$, and

$$
\begin{aligned}
l & =1209 \times 271 \times 2 \cdot 121 \times v_{2} / 54, \\
v_{2} & =1 / 88(1-\cdot 0002 \times 267) ; \\
\therefore \quad l & =15,440, \text { with } 10^{6} \text { dynes as unit. }
\end{aligned}
$$

Taking the absolute boiling-point at $\frac{2}{3}$ of the absolute critical temperature, as it nearly is for most liquids, we find for $\lambda$ by $(29)$ at $267^{\circ} \mathrm{C}$. the value 209 . This is at $267^{\circ}$, while at $0^{\circ}$ on our former reasoning the value found was 278 , and these two are in reasonable agreement, implying about 250 at $100^{\circ} \mathrm{C}$.

The main results of this section can be expressed in the two thermochemical equations

$$
\begin{aligned}
& 2 \mathrm{H}_{2} \mathrm{O}=\left(\mathrm{H}_{2} \mathrm{O}\right)_{2}+189 \times 2 \times 18 \mathrm{cal}, \\
& 3\left(\mathrm{H}_{2} \mathrm{O}\right)_{2}=2\left(\mathrm{H}_{2} \mathrm{O}\right)_{3}+177 \times 6 \times 18
\end{aligned}
$$

\section{The Viscosity of Water.}

In its viscosity water shows one of its most characteristic peculiarities, namely, the decrease of its viscosity with increase of pressure, discovered by Röntgen, and discussed by him in his theory of the constitution of water. We can make this phenomenon the subject of quantitative study, thanks to the refined measurements made by R. Cohen (Wied. Ann. xlv.). But it will be best to take the rariation with temperature first. At $0^{\circ}$ trihydrol is below its true physical melting-point, and accordingly we should expect the viscosity of the liquid trihydrol to be very great; on the other hand, dihydrol at 0 is probably tar above its melting-point, and must have a relatively small viscosity; therefore the viscosity of water at temperatures near $0^{\circ}$ must be mainly that of the trihydrol in it, the dihydrol gradually becoming of more importance as the temperature rises. 
It has been found that the viscosity $\eta$ of mixtures is not accurately expressible by a mixture-by-weight formula such as $\eta=p_{1} \eta_{1}+p_{2} \eta_{2}$, but Thorpe and Rodger (Journ. Chem. Soc. lxxi.) find the following type more successful -

$$
\eta=\left(\eta_{1} p_{1} v_{1}+\eta_{2} p_{2} v_{2}\right) /\left(p_{1} v_{1}+p_{2} v_{2}\right), \quad .
$$

which may be written in the form

$$
\eta v=\eta_{1} p_{1} v_{1}+\eta_{2} p_{2} v_{2} \text {. . . . . }
$$

As to variation of viscosity of a pure liquid with temperature, it seems to me best to use the equation of Graetz (Wied. Ann. xxxiv.),

$$
\eta=\mathrm{A}\left(t_{c}-t\right) /\left(t-t_{r}\right), \quad . \quad . \quad .
$$

where $t_{c}$ is the critical temperature and $t_{r}$ is a temperature some tens of degrees below the solidifying-point. Then for water we write

$$
\eta v=\mathrm{A}_{2} p_{2} v_{2} \frac{538-t}{t+x}+\mathrm{A}_{1} p_{1} v_{1} \frac{368-t}{t+150}, \quad . .
$$

assuming that dihydrol has $t_{r} 150$ below zero; because by analogy the solidifying-point of dihydrol must be low, and at any rate the second term on the right is of less importance than the first. Using the viscosities of water given by Hosking (Phil. Mag. [5] xlix.), we find

\begin{tabular}{|c|c|c|c|c|c|c|}
\hline ......... & $0^{\circ}$ & $20^{\circ}$ & $40^{\circ}$ & $60^{\circ}$ & $80^{\circ}$ & $100^{\circ}$ \\
\hline $10^{5} \eta_{2} p_{2} v_{2} \ldots \ldots \ldots \ldots$ & 1624 & 837 & 520 & 353 & 257 & 194 \\
\hline $10^{5} \eta_{1} p_{1} v_{1} \ldots \ldots \ldots \ldots$ & 172 & 159 & 144 & 130 & 116 & 103 \\
\hline $10^{5} \eta v$ calc. ......... & 1796 & 996 & 664 & 483 & 373 & 297 \\
\hline $10^{3} \eta v \exp . \ldots \ldots \ldots$ & 1794 & 1011 & 662 & 480 & 370 & 297 \\
\hline
\end{tabular}

$$
A_{2}=\cdot\left(002344, \quad x=33 \cdot 1, \quad A_{1}=\cdot 001222,\right.
$$

which give the comparison :-

\section{TABle XII.}

The discrepancy at $20^{\circ}$ illustrates the difficulty of getting mixture-formulæ to represent the viscosity of mixtures.

As to the effect of pressure on the viscosity of our mixture, we can differentiate (32) with respect to pressure $f$,

$$
\begin{aligned}
& p_{1} v_{1} \frac{d \eta_{1}}{d f}+p_{2} v_{2} \frac{d \eta_{2}}{d f} \\
& \quad=v \frac{d \eta}{d f}+\eta \frac{d v}{d f}+\left(\eta_{1} v_{1}-\eta_{2} v_{2}\right) \frac{d p_{2}}{d f}-p_{1} \eta_{1} \frac{d v_{1}}{d f}-p_{2} \eta_{2} \frac{d v_{2}}{d f^{\prime}}
\end{aligned}
$$


The terms on the right are now all known, as from Cohen's curves we can estimate with considerable accuracy $d \eta / \eta d f$ at $0^{\circ}$ when $d f$ is 200,400 , and 600 atmos respectively, namely $(305,224$, and 192$) \times 10^{-9}$, and the other data are contained in the previous sections. Thus in the three cases we get for the left side of $(35)$ the values $(55,56$, and 56$) \times 10^{-7}$. The greater part of these values must be due to $p_{2} v_{2} d \eta_{2} / d f$, so neglecting $p_{1} v_{1} d \eta_{1} / d f$ we find

$$
\frac{1}{\eta_{2}} \frac{d \eta_{2}}{d f}=\cdot 00034 ; . . . \quad \text {. . }
$$

that is to say, that an increase of pressure of 100 atmos causes the viscosity of trihydrol at $0^{\circ}$ to increase by $3 \cdot 4$ per cent. For ethyl oxide and benzene at $20^{\circ}$, Warburg and Sachs (Wied. Ann. xx.) found a corresponding percentage increase of $7 \cdot 3$ and $9 \cdot 3$, and Cohen for turpentine found 15 , and these are all more compressible liquids than trihydrol. In regard to viscosity, trihydrol behaves like a normal liquid, and the exceptional change of the viscosity of water under pressure is due to the dissociation caused by the pressure, which replaces some of the highly viscous trihydrol by the less viscous dihydrol. Cohen's curves show that at about $30^{\circ}$ the viscosity of water must be almost independent of pressure up to 1000 atmos; at this temperature the normal effect and the dissociation effect neutralise one another.

The preceding treatment of water's viscosity shows that the viscosity of aqueous solutions must be highly complicated on account of the action of the solute in altering the proportions of trihydrol and dihydrol in the solution. It is known that the viscosity of some aqueous solutions of solids is less than that of water itself. The reason for this surprising old fact is now apparent; the solute converts enough of the viscous trihydrol into the less viscous dihydrol to more than compensate for the increase of viscosity which its own presence imparts.

\section{Dielectric Capacity.}

Of the dielectric capacity of water and ice we have already made some study in section 2, for electric fields alternating with the frequency of light, since $n^{2}$ stands for $\mathrm{K}$, the dielectric capacity. But for $\mathrm{K}$ in more slowly alternating fields and in a steady field the experimental results are in apparent conflict. Thus Heerwagen (Wied. Ann. xlix.) and Drude (ibid. lix.) find a steady, almost linear diminution of $\mathrm{K}$ 
water with temperature from $0^{\circ}$ to $80^{\circ}$; while Thwing (Zeitsch. f. Phys. Chem. xiv.), with rapidly alternating oscillations (period not given), finds the capacity rise to a sharp maximum at $4^{\circ}$. In his measurements for different mixtures of alcohol and water at a fixed temperature, instead of a steady curve representing the variation of $K$ with composition, he gets a curve containing cusps at points which correspond to the formulæ $\mathrm{C}_{2} \mathrm{H}_{6} \mathrm{O}+6 \mathrm{H}_{2} \mathrm{O}, \mathrm{C}_{2} \mathrm{H}_{6} \mathrm{O}+3 \mathrm{H}_{2} \mathrm{O}$, and $\mathrm{C}_{2} \mathrm{H}_{6} \mathrm{O}+\mathrm{H}_{2} \mathrm{O}$; and similarly for mixtures of water with propyl alcohol, methyl alcohol, glycerine, and acetic acid, he gets cusps at points of definite molecular proportions. Drude (Zeitsch. f. Phys. Chem. xxiii.), on the contrary, gets a steady curve for $\mathrm{K}$ for water-alcohol mix tures running the same course as 'lhwing's with the cusps smoothed out. It looks, therefore, as if Thwing had used a period of vibration which was particularly sensitive to arrangements of electrons in regular order corresponding to the molecular proportions in his mixtures. His sharp cusp for water at $4^{\circ}$ is indicated by the following excerpts from his data :-

$\begin{array}{lccccc}\text { Temp. ........... } & 0^{\circ} & 2 \cdot 2^{\circ} & 4^{\circ} & 6^{\circ} & 7^{\circ} \\ \text { K ................ } & 79 \cdot 46 & 80 \cdot 84 & 85 \cdot 2 & 80 \cdot 84 & 79 \cdot 4\end{array}$

Otherwise his observations for water make $\mathbf{K}$ run with temperature a course very similar to that found by Drude and Heerwagen. If his cusp for water has the same significance as his cusps for other mixtures, we should have to take it as implying for water at $4^{\circ}$ the composition $\left(\mathrm{H}_{2} \mathrm{O}\right)_{3}+3\left(\mathrm{H}_{2} \mathrm{O}\right)_{2}$, that is, $\cdot 333$ trihydrol mixed with $\cdot 667$ dihydrol, while our formula (9) gives $\cdot 363$ with $\cdot 637$. An alteration in our somewhat arbitrarily chosen density of liquid trihydrol $(\cdot 88)$ at $0^{\circ}$ would ehange these proportions to .333 and $\cdot 667$; but until Thwing's remarkable observations have been confirmed by further special experiments, I should not feel quite warranted in making such changes in the constants of this paper as would make the composition of our standard mixture at $4^{\circ}$ to be $\left(\mathrm{H}_{2} \mathrm{O}\right)_{3}+3\left(\mathrm{H}_{2} \mathrm{O}\right)_{2}$. That ice near $0^{\circ}$ shows $\mathrm{K}$ of the order 78 when tested by electric oscillations of period about $10^{-1}$ to $10^{-2}$ second, and of the order 2 for periods of $10^{-6}$ and less, is a fact of prime importance in the relation of molecules to electrons. Dewar and Fleming's measurements of $\mathrm{K}$ at low temperatures bring out also the high promise of $\mathbf{K}$ for giving an insight into molecular architecture. But for the present the experimental data for water and ice hardly allow of more elaborate investigation than the above. 
8. The Melting of Ice as a Phenomenon of Dissociation, and the Higher Valency of Oxygen.

The polymerization of hydrol, which we have been studying, is only a special case of a general tendency of oxides, both organic and metallic, and other oxygen-containing compounds, to polymerize (see L. Henry, "The Polymerization of the Metallic Oxides," Phil. Mag. [5] xx.). This tendency is best explained by assigning to oxygen a higher valency than the dyad which it usually shows. Evidence for the tetrad nature of oxygen has been submitted by Friedel, Heyes: (Phil. Mag. [5] xxv.), and Brühl (Ber. d. Deut. Chem. Gesel. xxviii., xxx.). The tetrad valency may in reality be hexad sometimes; but on the principle of assigning the minimum valency that will explain the facts, we shall assume oxygren to be tetrad. The graphic formula for trihydrol then becomes that shown :-<smiles>OCO</smiles>

The centres of the three oxygen atoms determine a plane and a triangle in it, whose average shape must be equilateral. It is improbable that the hydrogen atoms lie in the same plane as the oxygen, but as their masses are small in comparison with those of the oxygen, the centre of mass of each $\mathrm{H}_{2} \mathrm{O}$ group is near to the centre of the oxygen atom in it, and the equilateral triangle must be the dominant feature of the molecule of trihydrol. The hexagonal form of the ice crystals and the formula of trihydrol both demonstrate that the domain of a molecule of ice is an equilateral triangular prism. As this is, I believe, the first case in which a definite shape has been ascertained for a molecule, it would be interesting in connexion with it to investigate systematically the properties of erystalline ice in different directions.

For dihydrol, on the same principle, the graphic formula will be this :-<smiles>O=CO</smiles>

There is a strong probability that in water some of the 
trihydrol is continnally dissocinting into dihydrol, and some of the dihydrol associating to trihydrol ; but the most striking dissociation of trihydrol into dihydrol is that which accompanies the melting of ice. Under a given pressure this occurs with remarkable definiteness at a corresponding temperature.

The thermodynamical discovery and explanation of the lowering of the melting-point of ice by pressure, though so justly famous in the history of the science of heat, give no clue to the mechanical or molecular cause of this remarkable phenomenon. In a solid body we assume the molecules so to hinder one another's motion, that each is kept vibrating within narrow limits round a certain point. With rise of temperature the mean distance between two neighbours increases, and when the distance increases to such an extent that the molecules can no longer hem one another in, they all start migrating, and the solid is said to melt. Now at the melting-point an increase of pressure, by forcing the molecules nearer to one another, ought to necessitate an increase of temperature to cause melting, for the increase of temperature would neutralize the effect of the increase of pressure. This is the molecular explanation for the usual fact that increase of pressure increases the melting temperature. But in the exceptional case of ice, although it expands with heat as long as it is ice, and shrinks under pressure, yet though pressure brings the molecules nearer together, they escape by melting at a lower instead of a higher temperature. Moreover ice at $0^{\circ}$ is a solid of very considerable rigidity, though it is on the very verge of melting. Its actual rigidity has not been measured, but as it has a Young's modulus between 20,000 and 90,000 (probably 70,000) kgms. weight per sq. cm.; that of glass at $15^{\circ}$ being 500,000 , and of silver 760,000 , it is evident that ice on the verge of melting still enjoys a remarkable degree of rigidity. The melting of ice is of an entirely different character from that of an ordinary physical melting. We have proved it to be accompanied by considerable dissociation. A simple conception of the dynamical cause of this dissociation can be oltained by following the lines of investigation of "A Kinetic Theory of" Soiids" and "Further Studies on Molecular Force" (I"hil. Mag. [5] xxxii. \& xxxix.). In these papers it is assumed that in solid compounds atomic motions are more important than molecular, because of Joule's and Kopp's law that each atom contributes a definite atomic heat. The atoms in the solid are still held by the chemical forces in their proper arrangement to form the molecule, but the molecules are so 
close to one another that the atoms of adjacent molecules jostle one another almost as freely as do the atoms within a single molecule. In the case of ice, by far the greater part of its heat-energy consists of the kinetic energy of the hydrogen and oxygen atoms, almost as if ice were a mechanical mixture of these, except that each oxygen atom and its two combined atoms of hydrogen influence one another's relative motions by the action of the chemical forces. In the same way in the molecule of trihydrol $\left(\mathrm{H}_{2} \mathrm{O}\right)_{3}$, the chemical forces must be regarded chiefly as controlling the $\mathrm{H}_{2} \mathrm{O}$ molecules into groups of three, thereby regulating their arrangement, but not seriously affecting the motion of the constituent atoms in any other way. Let us us name the oxygen atoms of $\left(\mathrm{H}_{2} \mathrm{O}\right)_{3} \mathrm{~A}, \mathrm{~B}, \mathrm{C}$. Then for each there is some point where the attractions of all other atoms for it are in equilibrium ; call these for the three oxygen atoms $\alpha, \beta, \gamma$, forming an equilateral triangle. Then on the average $A$ will vibrate through $a$ in a direction perpendicular to $\beta \gamma$ with an aniplitude $w$. The largest deformation of the equilateral triangle commonly occurring will be when $\mathrm{A}$ is displaced $w$ outwards and $\mathrm{B}$ and $\mathrm{C} w$ inwards, or what this configuration changes to in half a period of its vibration when $B$ and $C$ are displaced $w$ outwards and $\mathbf{A} w$ inwards. Let the side of the triangle be denoted by $\mathrm{D}$, then the deformation of the triangle would be conveniently measured by $w / \mathrm{D}$. When the deformation reaches a certain value, the chemical equilibrium of the three oxygren atoms becomes unstable, the bonds $\mathrm{AB} \mathrm{AC}$ may be said to break under the breaking-strain, or the electrons which form the chemical bonds swing round so that $B$ and $C$ are united by double bonds, and $A$ is free to assist in upsetting the equilibrium of a neighbour molecule of $\left(\mathrm{H}_{2} \mathrm{O}\right)_{3}$, and so the process goes on.

Now $\mathrm{D}$ and $w$ must both be regarded as functions of $f$ the pressure and $\mathrm{T}$ the absolute temperature. Now the fact that to melt ice at constant pressure we have to warm it up to the melting-point, shows that $w / \mathrm{D}$ increases with $\mathrm{T}$, as indeed we should expect to be the case. Again, from thermodynamics and experiment we know that if the pressure on ice is increased by 1 atmo, the melting-point falls by $\cdot 0075$ degree, and therefore $w / \mathrm{D}$ at constant temperature diminishes with increasing pressure. Both properties of $w / D$ would be accounted for by considering $D$ relatively more affected by pressure and lers by temperature than $v$. The dissociation of some of the trihydrol in water into dihydrol by increase both of temperature and pressure is explainable by these same properties of $w$ and $\mathbf{D}$. 
But these principles alone would lead us to expect that the melting of ice should be preceded by a stage of general softening, as with sealing-wax, on account of the occurrence of isolated cases of instability before all the molecules got to the unstable point. The sharpness with which the melting of ice occurs seems to me to indicate that we have to do with a phenomenon of molecular resonance. If the collisional forces were removed, and also the intermolecular, then under the chemical forces our triangle $\mathrm{ABC}$ would have a natural period of vibration round the equilateral shape of equilibrium. If the period of vibration of each of the atoms $A, B$, and $C$, on account of other attractions and collisions, becomes the same as this natural period, then by resonance small deformations of $\mathrm{ABC}$ will be worked up to large enough ones to attain the stage of instability. When some of the ice dissociates into dihydrol, this dissolves the remainder, altering for it both $w_{i} \mathrm{D}$ and the period of collisions, thus enabling it to exist.

The mechanical explanation of the melting of ice as a process of dissociation consists then of two parts : one accounting for the occurrence of a position of instability, the other accounting for the sharpness with which all the molecules attain this position simultaneously. The complete molecular or mechanical theory of the lowering of the melting-point of ice by pressure must then take account of the change not only of the deformation $x / \mathrm{D}$ with temperature and pressure, but also of the resonance.

If the surmise is correct that molecular resonance plays an important part in the melting of ice, then the dissociation of trihydrol presents an interesting similarity to that of rarefied ozone, to which 1 have drawn attention "The Spontaneous Change of Ozone into Oxygen, and a Remarkable Type of Dissociation," Phil. Mag. [5] xliii.). As rarefied ozone is gradually compressed, it begins at a pressure of $.14 \mathrm{~mm}$. of mercury to dissociate, because the average frequency of collisions between the molecules is the same is some natural frequency of vibration of the constituent atoms, or a simple multiple of it. This frequency must be of about the order $10^{8}$ per second. We can estimate the order of the frequency which is destructive to molecules of trihydrol in the following way :-From the known so-called molecular volumes of hydrogen and oxygen (really their molecular domains) we can infer that the oxygen atom occupies about $\frac{1}{3}$ of the space belonging to $\mathrm{H}_{2} \mathrm{O}$. Now the linear coefficient of expansion of ice being $000157 / 3$, the linear interspaces between the groups $\mathrm{H}_{2} \mathrm{O}$ of ice at $0^{\circ}$ centigrade 
(see "A Kinetic Theory of Solids") will be of the order $\cdot 000052 \times 273 \times 7$ times the mean diameter of the $\mathrm{H}_{2} \mathrm{O}$ group, but as the $\mathrm{H}$ atoms move four times as fast as the $\mathrm{O}$ atoms, and there are 2 of them to 1 of $O$ of about the same size, we may give the oxygen atoms an amplitude $\frac{1}{9}$ of the linear interspace allotted to each $\mathrm{H}_{2} \mathrm{O}$. The velocity of the $O$ atom is of the order $46,000 \mathrm{~cm}$. per sec., and the diameter of the $\mathrm{H}_{2} \mathrm{O}$ group of the order $2 \times 10^{-9} \mathrm{~cm}$., so the required frequency is of the order $46 \times 9 \times 10^{18} \div(2 \times 2 \times 7 \times 52 \times 273)$, or $10^{15}$ per sec. As the frequency for the most luminous part of the solar spectrum is of the order $5 \times 10^{14}$, we find that our calculated destructive frequency of vibration for the molecules of trihydrol must be about the same as that of some part of the measured solar spectrum, in which the frequency ranges from less than $10^{13}$ to about $10^{15}$ per sec. If resonance plays an important part in the melting of ice, then ice ought to absorb powerfully radiation of the right period, and to show anomalous dispersion in neightouringr parts of the spectrum. In the visible spectrum, ice show's no anomalous dispersion. The absorption spectrum of ice in the infra-red and ultra-violet regions would be worth study.

The laws of the dissciation of dihydrol $\left(\mathrm{H}_{2} \mathrm{O}\right)_{2}$ into hydrol, $\mathrm{H}_{2} \mathrm{O}$, could be worked ont by an examination of the behaviour of the vapour of water at pressures and temperatures up to and beyond the critical. It is probable that in ordinary water there is a little dissociation of dihydrol into hydrol. The question arises as to whether $\left(\mathrm{H}_{2} \mathrm{O}_{2}\right.$, can be split into positive and negative ions $\mathrm{H}_{2} \mathrm{O}$, the difference between which and the molecules of water-vapour would be the same as the differencs between the zine ion and the atom of zinc-vapour. The theory of electric conduction in aqueons solutions may be considerably affected by the possible participation of $\mathrm{H}_{2} \mathrm{O}$ ions.

The difference between the $\mathrm{H}_{2} \mathrm{O}$ molecule and the $\mathrm{H}_{2} \mathrm{O}$ ion could be expressed by saying that each negative $\mathrm{H}_{2} \mathrm{O}$ ion contained two negative electrons, whereas the molecule $\mathrm{H}_{2} \mathrm{O}$ contains a negative and a positive electron that equilibrate one another within the molecule. The formation of $\left(\mathrm{H}_{2} \mathrm{O}\right)_{2}$ consists then in two $\mathrm{H}_{2} \mathrm{O}$ molecules exchanging electrons, so that one bas two negative and the other two positive, which equilibrate as long as the $\left(\mathrm{H}_{2} \mathrm{O}\right)_{2}$ lasts. In $\left(\mathrm{H}_{2} \mathrm{O}\right)_{3}$ each $\mathrm{H}_{2} \mathrm{O}$ has a positive and a negative electron, but these, instead of equilibrating one another within the group, equilibrate with those of the other groups so as to hold the $\left(\mathrm{H}_{2} \mathrm{O}\right)_{3}$ together.

Mendeléeff, Crompton, and S. U: Pickering have shown by 
their elaborate examination of the delicate nuances in the physical properties of watery mixtures, that the alcohols, snlphuric acid, amines, and other compounds combine molecularly with water to form such bodies as $\mathrm{C}_{2} \mathrm{H}_{6} \mathrm{O}+12 \mathrm{H}_{2} \mathrm{O}, 3 \mathrm{C}_{2} \mathrm{H}_{6} \mathrm{O}$ $+\mathrm{H}_{2} \mathrm{O}, \mathrm{H}_{2} \mathrm{SO}_{4}+\mathrm{H}_{2} \mathrm{O}, \mathrm{H}_{2} \mathrm{SO}_{4}+6 \mathrm{H}_{2} \mathrm{O}$, and the like. These must be further examples of the tendency to polymerization due to the tetrad or higher valency of oxygen. "In water" of crystallization the same principle is at work. The methods of this paper can be applied to other associating liquids.

\section{Summary of Results.}

Ordinary water-vapour being $\mathrm{H}_{2} \mathrm{O}$, which it is proposed to call internationally hydrol, ice is trihydrol $\left(\mathrm{H}_{2} \mathrm{O}\right)_{3}$, and water a mixture of trihydrol and dihydrol $\left(\mathrm{H}_{2} \mathrm{O}\right)_{2}$, the proportions of which are determined by equations (7) and (9) up to $100^{\circ}$ and approximately to $200^{\circ}$. Probakly at its critical temperature water is practically pure dihydrol. The latent heat of fusion of ice is not an ordinary physical latent heat of fusion, but is mostly a latent heat of dissociation of trihydrol into dihydrol, partly masked by heat of solution of trihydrol in

TABLE XIII.

\begin{tabular}{|c|c|c|c|c|}
\hline & $\begin{array}{c}\text { Density } \rho \\
\text { at } 0^{\circ} \text {. }\end{array}$ & $\begin{array}{c}\text { Tennp.-coeff.of' } \\
\text { density, } h \text {. }\end{array}$ & $\begin{array}{l}\frac{n^{2}-1}{n^{2}+2} \cdot \frac{1}{\rho} \\
\text { at } 0^{\circ} \text {. }\end{array}$ & $\begin{array}{l}\text { Compressibility } \\
\text { per atmo at } 0^{\circ} \text {. }\end{array}$ \\
\hline Dibydrol ... & 1.08942 & 0009 & 20434 & $\cdot 000016$ \\
\hline \multirow[t]{2}{*}{ Trihydrol ... } & 88 & .0002 & .20968 & $000010 ?$ \\
\hline & $\begin{array}{l}\text { Surface- } \\
\text { tension at } 0^{\circ} \text {. }\end{array}$ & $\begin{array}{c}\text { Critical } \\
\text { temperature. }\end{array}$ & $\begin{array}{l}\text { Specific heat } \\
\text { at } 0^{\circ} \text {. }\end{array}$ & $\begin{array}{c}\text { Virial } \\
\text { Constant. }\end{array}$ \\
\hline Dihydrol & $78 \cdot 3$ & $368 \mathrm{C}$. & 8 & $16200 \times 10^{6}$ \\
\hline \multirow[t]{2}{*}{ Trihydrol ... } & $73 \cdot 32$ & $538 \mathrm{C}$. & $\cdot 6$ & $15400 \times 10^{6}$ \\
\hline & $\begin{array}{l}\text { Latent heat } \\
\text { of fusion. }\end{array}$ & $\begin{array}{c}\text { Latent beat } \\
\text { of evaporation } \\
\text { at } 100^{\circ} \text {. }\end{array}$ & $\begin{array}{c}\text { Viscosity at } \\
0^{\circ} .\end{array}$ & $\begin{array}{c}\text { Pressure-coeff. } \\
\text { of viscosity } \\
\text { per atmo. }\end{array}$ \\
\hline Dihydrol ... & ... & 257 cal. & 0030 & ... \\
\hline Trihydrol. & $16 \mathrm{cal}$. & 250 (near) & $\cdot 0381$ & $\cdot 00034$ \\
\hline
\end{tabular}

$2 \mathrm{H}_{2} \mathrm{O}=\left(\mathrm{H}_{2} \mathrm{O}\right)_{2}+189 \times 2 \times 18 \mathrm{cal} . \quad 3\left(\mathrm{H}_{2} \mathrm{O}\right)_{2}=2\left(\mathrm{H}_{2} \mathrm{O}\right)_{3}+177 \times 6 \times 18 \mathrm{cal}$. 
dihydrol. The latent heat of evaporation of water includes also the heat of dissociation of the dihydrol and trihydrol of water into the hydrol of steam. The specific heat of water is not an ordinary specific heat but includes a certain amount of heat of dissociation, Pressure dissociates trihydrol at rates given in Table VII.

In Table XIII. are the physical constants of the two ingredients of water given in C.G.S. units unless it is otherwise stated.

These results have mostly been obtained by application of the mixture formula on the assumption that no shrinkage or analogous change of properties takes place, and several of them depend on $\cdot 88$ the density of liquid trihydrol at $0^{\circ}$, which has been merely estimated by analogy from the density of ice.

Melbourne, July 1900.

XIVII. Experiments to Determine whether a Liquid when electrified loses any portion of its charye by Evaporation. By W. Craig Henderson, M.A., B.Sc., Trinity Collegye Cambridge, late 1851 Extitition Science Scholar*.

THE question whether the vapour rising from the surface of an electrified liquid is itself electrified or not. has received considerable attention during recent years; but unfortunately the various physicists who have made experiments on the subject have not all arrived at the same conclusion.

On the one hand a negative answer is given to the question by Blaket, by Schwalbe $\ddagger$, and by Sohncke $\$$; while on the other hand Exner $\|$ and Pellat 9 both answer the question in the affirmative. Each of these two physicists proceeds to apply this conclusion from his experiments to the case of evaporation of water from the earth's surface, and seeks thus to account partly for the electrification of the atmosphere. On consideration of Pellat's paper it seemed to me not inadvisable to make still one more investigation of the problem, and this idea was approved of by Professor J. J. Thomson.

In the experiments described below I have kept in view Pellat's application to the case of atmospheric electricity, and have therefore in the first place followed him in using only

* Communicated by Prof. J. J. Thomson, F.R.S.

$\dagger$ Blake, Wied. $A m n$. vol. xix. 1883, p. 518.

† Schwalbe, Ibid. vol lviii. 1896, p. 500 .

\$ Sohncke, Ibid. vol. xxxiv. 1888, p. 925.

II Exner, Sitzungsber. der Kaiserl. Akad. der Wissen. zu Wien, xciii. p. 222 (1886).

If Pellat, Journ. de Phys. 1899, May, p. 253. 